\section{ZEW}

Zentrum für Europäische Wirtschaftsforschung GmbH

Centre for European Economic Research

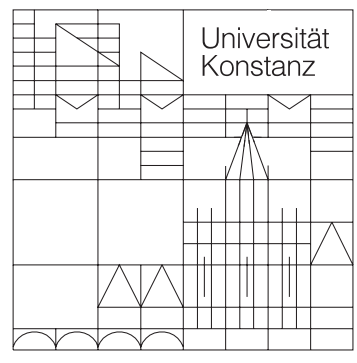

Rechts-, Wirtschafts- und Verwaltungswissenschaftliche Sektion Fachbereich

Wirtschaftswissenschaften

Diskussionspapiere der DFG-

Forschergruppe (Nr.: 3468269275):

Heterogene Arbeit: Positive und Normative Aspekte der Qualifikationsstruktur der Arbeit

Susanne Warning

Performance Differences in

German Higher Education:

Empirical Analysis of Strategic Groups

März 2004 
Diskussionspapier der Forschergruppe (Nr.: 3468269275) "Heterogene Arbeit: Positive und Normative Aspekte der Qualifikationsstruktur der Arbeit"

Nr. 04/09, März 2004

\title{
Performance Differences in German Higher Education: Empirical Analysis of Strategic Groups
}

\section{Susanne Warning}

\author{
Universität Konstanz \\ Fachbereich Wirtschaftswissenschaften \\ Fach D144 \\ 78457 Konstanz \\ Germany \\ mail: susanne.warning@uni-konstanz.de \\ phone: +49-7531-88-3359 \\ fax $+49-7531-88-4456$
}

\section{Zusammenfassung:}

Initial investments and different strategic actions of universities lead to their different positions in the higher education sector. Pursuing similar strategies leads to similar positions that influence structure and performance within the system. Institutions cannot only choose to focus on research or on teaching, but also to focus either on natural sciences or social sciences. Using 73 public universities in Germany, this paper examines the existence of strategic groups based on performance. Common strategic variables only partly determine performance in high and low efficiency groups. 
Short title:

Strategic Groups in German Higher Education

\title{
Performance Differences in German Higher Education: \\ Empirical Analysis of Strategic Groups
}

\author{
Susanne Warning \\ University of Konstanz
}

Address for correspondence:

Susanne Warning

University of Konstanz

Department of Economics, P.O. Box D-144

D-78457 Konstanz, Germany

Tel: +49-7531-883359, Fax: +49-7531-884456

Email: susanne.warning@uni-konstanz.de 


\begin{abstract}
Initial investments and different strategic actions of universities lead to their different positions in the higher education sector. Pursuing similar strategies leads to similar positions that influence structure and performance within the system. Institutions cannot only choose to focus on research or on teaching, but also to focus either on natural sciences or social sciences. Using 73 public universities in Germany, this paper examines the existence of strategic groups based on performance. Common strategic variables only partly determine performance in high and low efficiency groups.
\end{abstract}

Keywords: higher education, performance measurement, strategic groups

JEL: I21, L30, M11 


\section{Introduction}

German per capita income growth has been relatively low as compared to other European countries or the US. One of the many explanations for this difference could be the effectiveness and efficiency of a country's educational system. From this perspective, universities generate spill-over effects from their academic research and teaching (Audretsch et al., 2003), thereby stimulating economic growth. Indeed, the close nexus between the university system and economic growth has turned much attention to the efficiency and quality of German universities. The low competitiveness of German universities may be responsible for the 'brain drain' of high skilled researchers that has led to a situation in which not only the number of Nobel prizes awarded to researchers of German nationality has declined, but also that the odds that German Nobel Prize winners have conducted their research at foreign universities has grown. Finally, and perhaps most importantly, international university rankings based on publications and citations do not place German institutions among the top rank (see Kalaitzidakis et al., 2001 for economics).

This article analyzes competition among German universities using the concept of strategic groups. This framework is used to explain how and why universities differ in the degree to which they specialize in natural sciences or social sciences and in respect to the resources they devote either to research or teaching. The efficiency of universities is computed using Data Envelopment Analysis (DEA) to capture the different dimensions of university performance in one rating. Then common determinants of high and low efficiency universities are estimated by quantile regression.

I find that strategic variables that indicating emphasis on research or teaching do not explain the relative efficiency of universities. As to differences between social sciences and natural 
sciences, the fraction of publications in social sciences enhances efficiency. There is evidence that grants have an efficiency reducing effect in the high-performance group, independent of model specification. Being located in former West Germany is associated with increased efficiency in all specifications.

\section{The Concept of Strategic Groups and its Application to}

\section{Universities}

Universities have different missions, and accordingly are focused in a multitude of ways. Prior technological and strategic choices determine the position of each university within the higher educational system and may explain performance differences across different universities. Because of sunk costs a university will have little incentive to migrate to another technology despite performance deficiencies. There are different ways for universities to develop skills and to react to changing demands from firms or public policy, or to competitors' initiatives: they either can all react in the same way, or they may all react in different ways. But they also can react in line with some other universities, which results in similar positions of these institutions. In the latter case universities are clustered into groups which are characterized by similar strategies.

The idea of strategic performance-based groups within an industry was introduced by Caves and Porter (1977). They generalized the theory of "barriers to entry" to a "theory of mobility" (Caves and Porter, 1977, p. 250). Its essence is that differences in structural characteristics of firms within an industry systematically cause differences in performance. The strategic group concept argues that within an industry firms with similar asset configurations pursue similar 
strategies with similar performance results (Porter, 1979) in ways that cannot be explained by the structure-conduct-performance paradigm (Martin, 2002; Scherer and Ross, 1990).

This paradigm is extended by the idea that strategic behavior of individual firms influences both the structure and performance of an entire industry. While there are different strategic options among sectors of an industry, because of mobility impediments, not all options are available to every firm. Mobility barriers between the groups affect the degree of competition within the group. In this way, the "structure within the industry" influences firm profitability (Porter, 1979, p. 215). The high performance-group has an incentive to establish impediments to mobility to prevent other firms from entering its favored domain. Strategic variables represent mobility barriers and consequently may lead to performance differences. If the strategic variables can be changed easily, there should be no divisions into groups.

Much empirical research based on the concept of strategic groups has analyzed performance differences among groups within industries. Empirical evidence is mixed. Nair and Kotha (2001) (for the steel industry) and McNamara et al. (2002) (for banks) find evidence for the existence of strategic groups. But other studies, like Kling and Smith (1995) (for the airline industry) or Nath and Gruca (1997) (for hospitals) do not. Although the strategic group concept has been applied to publicly financed industries such as hospitals (Nath and Gruca, 1997; Dalmau-Atarrodona, 1998), it does not seem to have been applied to universities. This paper attempts to use strategic groups to analyze competition in higher education. Dimensions along which universities can strategize are the trade-off between teaching and research on the one hand, and between natural sciences and social sciences on the other. 
High impediments, and therefore low mobility, are expected for research intensive universities, while low impediments are present at teaching intensive universities. While academic research is associated with very specific human capital, the skills required for teaching are more general. Because high quality researchers are scarce, the distribution of this resource should reveal more significant differences among universities in research than in teaching. Varying the number of students is less costly than varying the output of published research papers. This leads to the first hypothesis that the higher the publication to graduate ratio, the higher will be the efficiency.

Finally, we not only expect different mobility barriers between research and teaching but also between natural and social sciences. Impediments to mobility appear to be higher in natural sciences than in social sciences because most natural scientists need laboratory space for carrying out their research and teaching. Since these investments in laboratories and apparatus are expensive, mobility barriers in the natural sciences are higher than in the social sciences. As a consequence, it is more expensive for a university to hire a new researcher in natural sciences than in social sciences, as mostly new infrastructure must be built up for specialization purposes and technological inventions. Also, academic research in the natural sciences is usually conducted in large groups. Hiring one natural scientist induces additional expenditures for staff and special laboratory equipment. The impediments are then higher for those universities with relative large natural science departments and lower for those with larger departments in the social sciences. Consequently, these institutions differ in performance and in their position in the higher education system. The second hypothesis consequently states that the higher the fractions of social sciences, both in research and in teaching is, the lower is the performance of a university. To measure performance, efficiency scores generated by Data Envelopment Analysis are used, as explained in the next section. 


\section{Performance Measurement in Universities}

\section{The Method: Data Envelopment Analysis}

Performance measurement in universities is based on efficiency and mostly carried out by a method applying linear programming. The basic assumption is that universities are multiproduct organizations which 'produce' at least two different outputs, research and teaching, using multiple inputs. Generally accepted outputs of the university production process are the number of graduates as a proxy for teaching (Avkiran, 2001; Athanassopoulos and Shale, 1997) and the number of publications as a proxy for research (Thursby, 2000; Johnes and Johnes, 1993). Unfortunately, performance rankings based on publications and citations suffer from two shortcomings: first, research is not the sole purpose of a university, so overall rankings should consider more than just publications; second, rankings based on publications and citations do not reflect efficiency. Performance rankings should evaluate universities based on an input-output analysis. Prominent inputs used to generate these outputs are expenditures for staff, for library and for further infrastructure. The performance of a university is measured by how well it transforms inputs into outputs (Thursby, 2000; Johnes, 1999).

Performance evaluation in public universities is based on multiple inputs and outputs. Thus, regressions based on only one output are not appropriate. This study employs Data Envelopment Analysis (DEA), a non-parametric estimation procedure based on linear programming and first introduced by Charnes et al. (1978). In a first step, the frontier is drawn up by the efficient units. As a second step, hypothetical units are generated on the frontier to serve as reference units for inefficient universities. These reference units are 
constructed as linear combinations of the most efficient units on the frontier. All inefficient units are enveloped by the frontier. On the basis of the empirical production function, in terms of best practice, DEA reveals the universities on the efficient frontier. DEA indicates the level of inefficiency of each institution, compared to the efficient universities.

The method closest to DEA and widely used in estimating parametric production functions is the Stochastic Frontier Analysis (SFA) (Aigner et al., 1977). Here, two random variables are considered, one accounting for measurement errors and the other one for random factors. The main advantages of SFA over DEA are the estimation of error terms and the estimation of specific production functions such as CES or Cobb-Douglas. Both drawbacks of applying DEA are considered in this study. First, we apply quantile regressions to capture stochastic factors. The efficiency scores are taken as the endogenous variables. Since DEA offers deterministic scores, we overcome the problem of correlation between the error term of the quantile regression and the efficiency score. Secondly, in contrast to the stochastic frontier approach, DEA determines an empirical production function in terms of best practice where no specific functional relationship is assumed and multiple outputs can be considered. This flexibility seems to be more appropriate since there is no generally accepted functional form of the production function of a publicly funded university. Furthermore, in this case, there is no theoretical argument to the relative importance of inputs and outputs.

Formally, the so-called output-oriented envelopment-form of the DEA with constant returns to scale is computed as presented in (1). 


$$
\begin{array}{cc}
\max _{\theta, \lambda} \theta & \\
\text { subject to } \sum_{j=1}^{n} y_{r j} \lambda_{j} \geq \theta y_{r k} \quad(r=1,2, \ldots, s) \\
\sum_{i=1}^{m} x_{i j} \lambda_{j} \leq x_{i k} \quad(i=1,2, \ldots, m) \\
\lambda_{j} \geq 0 \quad(j=1,2, \ldots, m+s)
\end{array}
$$

Assume there are $n$ universities and each uses $m$ inputs to produce $s$ outputs. University $j$ uses the amount $x_{i j}$ of input $i$ to produce the amount $y_{r j}$ of output $r$. The variables $\lambda_{\mathrm{j}}$ are used to identify the influence of the reference unit. From these multipliers virtual units are generated which act as comparative points on the efficient frontier. The peer group of each university is indicated by positive values of $\lambda_{j}$ in the optimum. The constraints ensure that the reference unit produces at least as much of all outputs while consuming at most the same amount of inputs as the observed unit. The variable $e_{k}=1 / \theta$ is the maximal value for university $k$ by which all output can be proportionally raised, subject to all constraints.

The increasing impact of human capital on economic growth and the scarce resources of states to finance their universities have lead to an increasing application of the DEA models to analyze the efficiency of universities ${ }^{1}$. Based on the demand for comparability of university performance in different countries, efficiency analyses as performance evaluation of the whole university system on the institutional level have been carried out during recent years.

\footnotetext{
1 Examples are Thursby (2000) for US doctoral programs in economics, Ng and Li (2000) for Chinese institutions of higher education, Johnes (1999) for the UK universities, and Avkiran (2001) for Australian universities.
} 


\section{Data and Model Specifications for the Efficiency Analysis}

The data set includes 73 publicly funded universities in Germany. Specialized universities like medical universities as well as the three private universities are excluded ${ }^{\natural}$. German universities do not vary significantly in their financial inputs, because the overwhelming majority of financing is provided by the government, which does not differentiate among universities. Inputs used measure staff, both scientific and non-scientific, and overhead expenditures, including spending on library resources, computing services and further infrastructure. Data are provided by the Federal Statistical Office of Germany.

Given these resources, universities maximize a variety of outputs. These conflicting goals are captured by computing five different DEA-scores. The first specification - called publicationmodel - measures research efficiency. It is based on Science Citation Index (SCI) data for the natural sciences and on the Social Science Citation Index (SSCI) and the Arts and Humanities Index (AHI) for the social sciences. Since the ISP incorporates only quality journals in its indexes, the computed score provides information on both quality and quantity of publications. The 'publication' variable includes the total number of publications from 1997 to 1999, amounting to 14,176 in the SCI and 893 in the SSCI and AHI. These different numbers reflect differences in publication activity across natural sciences and social sciences. The expenditures on personnel per university are about 100,437,000 Euro. On average, 30,400,000 Euro were spent for infrastructure in 1998.

The second DEA score is the graduate-model. It is designed to measure teaching efficiency, based upon graduation counts per discipline. The category sciences (SC) include graduates

\footnotetext{
${ }^{2}$ The private universities are highly specialized, focusing on either business or on business and medicine.
} 
from mathematics, medicine, agriculture, engineering, and, of course, chemistry, biology and physics. The social sciences (SSC) category contains graduates from law, economics, social sciences, languages, and arts. The average number of graduates in the SSC and the SC subjects in 1998 was 985 . Table 1 presents the descriptive statistics of the included inputs and outputs.

\{Insert Table 1 here $\}$

To capture the strategic option to devote different shares of total resources to either natural sciences or social sciences, two additional scores for each university are computed (SCImodel, SSCI-model). Finally, a score measures the overall efficiency of the universities. It includes information on all aspects mentioned above. These specifications are summarized in table 2 .

\{Insert Table 2 here $\}$

\section{Results of the Performance Measurement}

The estimated efficiency scores are in the interval from zero to one. Universities achieving a score of one are called efficient. As strategic groups within the university system are identified on the basis of performance, the relationship between the scores of different DEA model specifications is examined. The correlation results might give a hint of the existence or non-existence of strategic groups. However, inputs are the same in all models, since they cannot be separated for research and teaching, or for social sciences and natural sciences.

\footnotetext{
${ }^{3}$ ISI Web of Science provides access to the Social Science Citation Index (SSCI), the Science Citation Index
} 
Therefore, substitution effects cannot be identified. The results for different output specifications are summarized in table 3.

\{Insert Table 3 here $\}$

The average efficiency in teaching is significantly higher than in research and also the standard deviations differ significantly. Efficiency is higher in the publication-model. A similar result can be shown for natural sciences and social sciences: the average efficiency in natural sciences is significantly higher than in social sciences; however the standard deviations do not differ significantly. Not surprisingly, the total model reveals highest average efficiency because it is composed from the different models.

The correlation between the efficiency score from the publication-model (M1) and the graduate-model (M2) is rather low, and so is the correlation of the scores between the SSCI (M3) and the SCI (M4) model. All correlation coefficients - generated as correlations of the efficiency score computed using one model with the efficiency score using another model with individual universities as observations - are shown in table 4. Since the correlation is not very high across all specifications, the models capture the differing foci of individual universities.

\{Insert Table 4 here $\}$

The correlation matrix provides some information regarding existing groups. If a university focuses mostly on research or mostly on teaching, it would be expected that it should have

(SCI) and the Arts and Humanities Index (AHI). 
high performance in one field and low in the other, thus resulting in negative correlation between the graduate- and the publication-model. The low correlation between the research and the teaching efficiency scores suggests that there is no group structure based on performance differences. Professors do both research and teaching and distribute their time budget independently on each task. The same argumentation holds for the correlation between the social sciences and the natural sciences score.

\section{The Impact of Strategic Variables on Performance of German Universities}

This paper measures the efficiency of the university system in Germany. The results show differences in average efficiency between research and teaching as well as differences in average efficiency between natural sciences and social sciences. These performance differences might be due to a common structure with high- and low-performance universities. Groups may have common structural elements that predict the performance of a university by common variables. As determinants of efficiency three groups of variables are applied as exogenous variables: strategic variables, university characteristics, and competitive variables.

While most studies apply cluster analysis to identify strategic groups, this paper identifies common strategic variables in the high and in the low performance groups by quantile regression. In the simplest form of this semi-parametric technique, the least absolute deviation estimator fits the median to a linear function of covariates. Quantile regression is potentially attractive for the reason that the median or other quantiles as a measure of location are robust against outliers. Theory predicts performance differences across groups of universities, suggesting that universities with similar characteristics may be grouped into 
either a high- or low-performance group. To identify common variables of these different groups, quantile regression is applied to detect the impact of variables in different quantiles (see Buchinsky, 1998). We use the 25 percent and the 75 percent quantile. The 75 percent quantile focuses on the high efficiency group and consequently on the 'highly efficient universities'. This means that 75 percent of the universities have an efficiency score which is lower than the boundary and 25 percent of the universities have higher efficiency scores. The opposite holds for the 25 percent quantile. The low-performance group is defined by the 25 percent quantile.

As exogenous variable and performance measure, the efficiency score of the total model (M5) is used. The higher the value of the score, the more efficient the university is. Thus, a positive sign on estimated coefficients indicates an efficiency enhancing effect. Following Gonzalez-Fidalgo and Venura-Victoria (2002) it is assumed that the degree of efficiency may be affected by three groups of variables: strategic variables as suggested by the concept of strategic groups, industry variables, and environmental variables.

First, there are strategic variables under the control of university administrators. Such variables may reflect the choice of emphasizing either research or teaching. These variables can be measured by the publication/graduate ratio both for social sciences (SSCIpublication/grad) and natural sciences (SCI-publication/grad). The higher barriers to mobility in research as compared to teaching predicts an efficiency enhancing effect of the publication/graduate ratio and thus a positive sign. This effect may be stronger in natural sciences than in social sciences. 
The proportion of social sciences publications (graduates) in the total number of publications (graduates), fracSSCIpublications (fracSSCIgraduates), can be interpreted as another strategic variable that reveals concentration on social sciences. The higher the fraction of SSCI publications or SSCI graduates, the higher the impact of the social sciences. Thus the social sciences variables are expected to lead to an efficiency reducing effect, as there seem to be lower barriers to mobility in social sciences than in natural sciences. Consequently, a negative sign is expected for both variables. Because research is connected with higher barriers to mobility, the coefficient of the fraction of social sciences publications is expected to be more important than the corresponding graduate variable.

Furthermore, universities also control efforts to attract external financing to enhance their inputs. As a proxy for such income, the amount of research grants (grants) in 1998 is incorporated. This additional input might reduce performance in terms of efficiency and result in a negative coefficient because often these resources are designated for particular projects or consulting and thus might not lead to either more graduates or publications.

The second and the third group of included variables are mainly out of the control of universities as consequence of previous investments. The second group considers university characteristics that cannot be changed by the institution in the short term and might affect performance. Universities with a medical school usually operate a hospital and therefore have a different financing structure. The dummy variable medicine captures this effect. Furthermore, it is well known that the reputation of a university is an important factor to both students and to researchers. Since it needs time to build up a "stock" of reputation, the age of the university is incorporated to capture this path-dependent effect (age). Reputation might increase with the age of a university but at a decreasing rate. To control for a non-linear 
influence of age, the squared term is included (age 2$)$. Number of students (students) is incorporated to capture size effects.

The location of a university also could influence its performance. Thus we control by the number of residents in the town in which the university is located (inhabitants). Since German students are less likely to relocate compared to students in the U.S., universities in larger cities, facing high demand, may have less of an incentive to increase their performance. Finally, a dummy variable is included for location in former West Germany (west) that controls for different endowment effects. In the ten years since reunification, universities located in the former East Germany received more grants than those universities in the former West Germany. Thus, this transition effect may result in a lower efficiency of former East German universities.

The third group contains variables to control for the competitive environment of universities. As a result of the low mobility of students across state lines, the Herfindhal-index $(H)$ of students is considered separately for each state. A university's direct competition is captured by the number of universities in the town (no_univ). The descriptive statistics of these exogenous variables are presented in table 5.

\{Insert Table 5 here $\}$

The following model considers the three groups of exogenous variables and is estimated to identify the impact of teaching and research related variables on performance of universities:

Efficiency $e_{k}=\beta_{1}+\beta_{2} *$ SSCI-(publication $/$ grad $)+\beta_{3} *$ SCI-(publication $/$ grad $)+\beta_{4} *$ grants 


$$
\begin{aligned}
& +\beta_{5} * \text { students }+\beta_{6} * \text { medicine }+\beta_{7} * \text { age }+\beta_{8} * \text { age } 2+\beta_{9} * \text { inhabitants } \\
& +\beta_{10} * \text { west }+\beta_{11} * H+\beta_{12} * \text { no_univ }+u
\end{aligned}
$$

The following model indicates the impact of natural science and social science related variables:

Efficiency $e_{k}=\beta_{1}+\beta_{2} *$ fracSSCIpublications $+\beta_{3} *$ fracSSCIgraduates $+\beta_{4} *$ grants

$$
\begin{aligned}
& +\beta_{5} * \text { students }+\beta_{6} * \text { medicine }+\beta_{7} * \text { age }+\beta_{8} * \text { age } 2+\beta_{9} * \text { inhabitants } \\
& +\beta_{10} * \text { west }+\beta_{11} * H+\beta_{12} * \text { no_univ }+u
\end{aligned}
$$

Both models are estimated for the high- and the low-efficiency group for every specification. The empirical results in table 6 show the impact of the teaching and research related variables on university performance. Neither the publication/graduate ratio in social sciences nor in natural sciences seems to have a significant effect on efficiency for the high- or the lowperformance group. Universities cannot be characterized by common variables in the different performance groups. Consequently, no group structure can be identified that is based on the underlying variables.

\{Insert Table 6 here\}

While the coefficient of the publication/graduate ratio is positive for social sciences, it is negative for natural sciences. Neither in the high- nor low-efficiency groups do these strategic variables have a statistically significant impact. The SSCI publication/graduate ratio impact is higher than the SCI impact despite lower barriers to mobility. Increasing importance of publications - as expected - increases efficiency only for the social sciences, but not for 
natural sciences; although these effects are not statistically significant. The variable grants shows the expected negative sign, but it is only significant for the high-performance universities. From the group of variables reflecting university characteristics the dummy for a medical school increases efficiency significantly in the low-performance group. The only variable that has a significant impact on performance in both groups is location in the former West Germany with a statistically positive coefficient. All other variables remain insignificant for the 25 percent and the 75 percent quantiles. Accordingly, there seems to be no evidence for the existence of strategic groups regarding research and teaching based on common variables.

The second set of estimations reveals differences among the kind of research and the kind of education. The results in table 7 predict differences between disciplines. Contrary to the theory, the proportion of publications in social sciences influences efficiency in a significantly positive fashion in the high- and low-performance groups. Although the impact of variables defining the group structure is partly different from the expectation, the significant result of the strategic variables supports the existence of a group structure regarding the kind of science. Like in the research-teaching estimations, grants have a statistically significant efficiency reducing impact in the high-performance group. The dummy for hosting a medical school at the university increases efficiency in the lowperformance group. Again, efficiency is significantly higher when the university is located in the former West Germany.

\{Insert Table 7 here $\}$ 
Finally, strategic variables in research and teaching do not have a significant impact on the efficiency of German universities, in any group. As performance differences cannot be characterized by common strategic variables there seem to be no groups in the higher educational system based either on different teaching or on research. However, the strategic variables in social sciences and natural sciences are discovered to influence the efficiency of universities significantly. In this way, universities can be characterized by common variables and divided into groups based on performance. As the impact between teaching and research variables varies there are strategic groups related to social sciences and natural sciences but they are not based upon the barriers to mobility. Apart from these strategic variables, the dummy variable for location in the former West Germany enhances efficiency in every specification, which can be explained by higher demand from students, better relationships with industry and greater research grants by outside firms.

\section{Conclusion}

As a result of initial strategic choices, universities differ. Based on different performance levels a group structure within the industry may occur. Dimensions along which universities could act strategically are the relation between research and teaching and the importance of social sciences compared to natural sciences. While a group structure cannot be revealed regarding to research and teaching, there is evidence for one distinguishing natural sciences from social sciences.

Based on a unique dataset of 73 publicly funded German universities, relative efficiency as a performance measure of these non-profit organizations is calculated by applying the nonparametric approach of Data Envelopment Analysis (DEA). It was shown that universities 
differ in their strategic orientation indicated by differences in efficiency. It is greater in teaching than in research, and it is also greater in natural sciences than in social sciences.

This is the first time both non-parametric DEA estimations and semi-parametric regressions have been applied to German universities. In contrast to studies from other industrial sectors, group formation is based on the economically founded variable of efficiency.

Given the two strategic dimensions - teaching versus research, and social sciences versus natural sciences - common determinants of efficiency are examined for the high- and the low efficiency group in a model that considers all outputs simultaneously. It turns out that strategic variables such as the publication/graduate ratio both in social sciences and in natural sciences do not influence performance significantly. But the fraction of publications in social sciences of the total number of publications has a significantly positive impact on efficiency, both in the high- and the low-performance group. Location in the former West Germany always had a significant positive impact on efficiency. Competitive environment and other static characteristics of the university show no impact in explaining strategic groups.

The results provide evidence that universities in Germany differ regarding their level of efficiency and the underlying effects. Efficiency not only seems to be influenced by university characteristics or environmental factors, but also by strategic variables in terms of focusing on social sciences versus natural sciences. Policy makers could encourage those strategic effects by increasing incentives and rewards for more efficient universities. This could harness competition to overcome the existing lack of efficiency in the mainly undifferentiated and less competitive sector of higher education. An increase in the competitiveness of universities may then increase both the quality and quantity of academic 
research and graduates and thus may help to improve the international competitiveness of German universities and firms in the long run. 


\section{Acknowledgements}

I am grateful to David B. Audretsch, Rui Baptista, Richard Caves, Oliver Fabel, Guenter Franke, Jens C. Jackwerth, Adam Lederer, Erik E. Lehmann, Erik Lueders, Thomas Pluemper, John J. Siegfried and Peter Welzel for their very helpful comments. The paper also benefited from presentations at the International Industrial Organization Conference in Boston and the IAAEG in Trier. Financial support by the German Research Foundation (DFG) through the research group \#FOR454 'Heterogeneous Labor' at the University of Konstanz and at the ZEW Mannheim, is gratefully acknowledged. Parts of this paper were written while visiting the Institute for Development Strategies at the School of Public and Environmental Affairs, Indiana University, Bloomington. The discussions at the Institute are greatly appreciated. 


\section{References}

Aigner, Dennis J., C. A. Knox Lovell, and Peter Schmidt (1977) 'Formulation and Estimation of Stochastic Frontier Production Models', Journal of Econometrics, 6, 21-36.

Athanassopoulos, Antreas D., and Estelle Shale (1997) 'Assessing the Comparative Efficiency of Higher Education Institutions in the UK by Means of Data Envelopment Analysis', Education Economics, 5, 117-134.

Audretsch, David. B., Erik E. Lehmann, and Susanne Warning (2003) 'University Spillovers: Strategic Location and New Firm Performance', CEPR Discussion Paper No. 3837.

Avkiran, Necmi K. (2001) 'Investigating technical and scale efficiencies of Australian Universities through Data Envelopment Analysis', Socio-Economic Planning Sciences, 35, 57-80.

Buchinsky, Moshe (1998) 'Recent Advantages in Quantile Regression Models', Journal of Human Resources, 33, 88-126.

Caves, Richard., and Michael. E. Porter (1977) 'From Entry Barriers to Mobility Barriers: Conjectural Decisions and Contrived Deterrence to New Competition', Quarterly Journal of Economics, 91, 241-261.

Charnes, Abraham, William W. Cooper, and Edwardo Rhodes (1978) 'Measuring the Efficiency of Decision Making Units', European Journal of Operational Research, 2, 429-444.

Dalmau-Atarrodona, Eulália (1998) 'Market Structure and Hospital Efficiency: Evaluating Potential Effects of Deregulation in a National Health Service', Review of Industrial Organization, 13, 447-466. 
Gonzalez-Fidalgo, Eduardo, and Juan Venura-Victoria (2002) 'How Much Do Groups Matter?', Review of Industrial Organization, 21, 55-71.

Johnes, Geraint, and Jill Johnes (1993) 'Measuring the Research Performance of UK Economics Departments: An Application of Data Envelopment Analysis', Oxford Economic Papers, 45, 332-347.

Johnes, Geraint (1999) 'The Management of Universities', Scottish Journal of Political Economy, 46, 505-522.

Kalaitzidakis, Pantelis, Theofanis P. Mamuneas, and Thanasis Stengos (2001) 'European Economics: An Analysis Based on Publications in the Core Journals - An Update', European Economic Review, 43, 1150-1168.

Kling, James A., and Ken A. Smith (1995) 'Identifying Strategic Groups in the US Airline Industry: An Application of the Porter Model', Transportation Journal, 35, 26-34.

Martin, Stephan (2002) Advanced Industrial Economics, Second Edition, Oxford, Blackwell Publishers.

McNamara, Gerry M., Rebecca A. Luce, and George H. Tompson (2002) 'Examining the Effect of Complexity in Strategic Group Knowledge Structures on Firm Performance', Strategic Management Journal, 23, 153-170.

Nair, Anil, and Suresh. Kotha (2001) 'Does Group Membership Matter? Evidence from the Japanese Steel Industry', Strategic Management Journal, 22, 221-235.

Nath, Deepika, and Thomas S. Gruca (1997) 'Convergence Across Alternative Methods for Forming Strategic Groups', Strategic Management Journal, 18, 745-760. 
Ng, Ying C., and Sung K. Li (2000) 'Measuring the Research Performance of Chinese Higher Education Institutions: An Application of Data Envelopment Analysis', Education Economics, 2, 139-156.

Porter, Michael E. (1979) 'The Structure within Industries and Companies' Performance', The Review of Economics and Statistics, 61, 214-227.

Scherer, Frederic M. and David Ross (1990) Industrial Market Structure and Economic Performance, Third Edition, Boston, Houghton Mifflin.

Thursby, Jerry G. (2000) 'What Do we Say about Ourselves and What Does it Mean? Yet Another Look at Economics Department Research', Journal of Economic Literature, 38, 383-404. 


\section{Tables}

Table 1: Descriptive statistics of the inputs and output of the DEA model

\begin{tabular}{lcccc}
\hline Variable & Mean & Minimum & Maximum & Std. Dev. \\
\hline Expenditure on personnel (in 1000 EURO) & $100,437.25$ & $3,669.06$ & $247,575.37$ & $58,968.06$ \\
Other expenditure (in 1000 EURO) & $30,399.84$ & $1,714.88$ & $83,756.82$ & $20,523.70$ \\
SSCI Publications 1997-1999 & 181.548 & 0 & 893 & 184.767 \\
SCI Publications 1997-1999 & 2280.164 & 1 & 14,176 & 2453.271 \\
SSCI graduates 1998 & 984.904 & 0 & 3973 & 794.292 \\
SCI graduates 1998 & 984.534 & 1 & 3115 & 752.044 \\
\hline
\end{tabular}


Table 2: DEA model specifications

\begin{tabular}{|c|c|c|}
\hline & Inputs & Outputs \\
\hline \multirow[t]{2}{*}{ Publication-Model (M1) } & Expenditure on personnel & SSCI Publications \\
\hline & Other expenditure & SCI Publications \\
\hline \multirow[t]{2}{*}{ Graduate-Model (M2) } & Expenditure on personnel & SSCI Graduates \\
\hline & Other expenditure & SCI Graduates \\
\hline \multirow[t]{2}{*}{ SSCI Model (M3) } & Expenditure on personnel & SSCI Publications \\
\hline & Other expenditure & SSCI Graduates \\
\hline \multirow[t]{2}{*}{ SCI Model (M4) } & Expenditure on personnel & SCI Publications \\
\hline & Other expenditure & SCI Graduates \\
\hline \multirow[t]{4}{*}{ Total Model (M5) } & Expenditure on personnel & SSCI Publications \\
\hline & Other expenditure & SCI Publications \\
\hline & & SSCI Graduates \\
\hline & & SCI Graduates \\
\hline
\end{tabular}


Table 3: Descriptive statistics of the efficiency scores

\begin{tabular}{lccccc}
\hline & M1 & M2 & M3 & M4 & M5 \\
& & & & & \\
\hline Mean & 0.449 & 0.628 & 0.460 & 0.586 & 0.719 \\
Maximum & 1 & 1 & 1 & 1 & 1 \\
Minimum & 0.001 & 0.108 & 0.014 & 0.005 & 0.165 \\
Std. Dev. & 0.297 & 0.232 & 0.301 & 0.267 & 0.236 \\
Number of efficient universities & 4 & 5 & 3 & 5 & 13 \\
\end{tabular}


Table 4: Correlation matrix of the efficiency scores

\begin{tabular}{cccccc}
\hline & M1 & M2 & M3 & M4 & M5 \\
\hline M1 & 1.000 & - & - & - & - \\
M2 & 0.188 & 1.000 & - & - & - \\
M3 & 0.834 & 0.351 & 1.000 & - & - \\
M4 & 0.217 & 0.750 & 0.073 & 1.000 & - \\
& & & & & \\
M5 & 0.594 & 0.835 & 0.682 & 0.620 & 1.000 \\
\hline
\end{tabular}


Table 5: Descriptive statistics for the independent variables in the regression analysis

\begin{tabular}{lcccc}
\hline Variable & Mean & Std. Dev. & Minimum & Maximum \\
\hline grants & $24,099.6$ & $22,516.8$ & 168.4 & $107,132.5$ \\
students & $15,730.2$ & $11,665.3$ & 9 & 57,125 \\
age & 175.9 & 191.6 & 8 & 616 \\
inhabitants & 477,004 & 717,725 & 15,818 & $3,410,000$ \\
West & 0.7945 & - & 0 & 1 \\
Medicine & 0.4384 & - & 0 & 1 \\
\end{tabular}


Table 6: Estimation results of the Quantile Regression for the total model (M5) to identify impact of the relation between Research and Teaching Endogenous Variable: Efficiency

\begin{tabular}{|c|c|c|}
\hline Variable & $\begin{array}{c}\text { 25\%-Quantile } \\
\text { Coefficient (t-value) }\end{array}$ & $\begin{array}{c}\text { 75\%-Quantile } \\
\text { Coefficient (t-value) }\end{array}$ \\
\hline SSCI-(publication/graduates) & $0.0027(0.01)$ & $0.0004(0.01)$ \\
\hline SCI-(publication/graduates) & $-0.0174(0.51)$ & $-0.0072(0.23)$ \\
\hline Grants & $-0.5690(0.22)$ & $-2.9200(2.06)^{* *}$ \\
\hline Students & $2.2900(0.36)$ & $4.1400(0.75)$ \\
\hline Medicine & $0.2070(1.78)^{*}$ & $0.0656(0.78)$ \\
\hline Age & $0.0001(0.25)$ & $-0.0002(0.55)$ \\
\hline $\operatorname{Age}^{\wedge} 2$ & $-0.0258(0.21)$ & $0.0549(0.61)$ \\
\hline Inhabitants & $-0.0453(0.22)$ & $-0.0967(0.75)$ \\
\hline West & $0.2679(2.69)^{* * *}$ & $0.2602(2.50)^{* *}$ \\
\hline $\mathrm{H}$ & $-0.0144(0.04)$ & $-0.3110(1.03)$ \\
\hline No of universities & $-0.1096(0.66)$ & $0.0166(0.10)$ \\
\hline Constant & $0.3843(0.86)$ & $0.8259(2.56)^{* *}$ \\
\hline Pseudo R-squared & 0.3780 & 0.3283 \\
\hline
\end{tabular}

The coefficients for students, grants, age ${ }^{\wedge} 2$ and inhabitants are multiplied by 100,000 .

***significance level $0.01 ; * *$ significance level $0.05 ; *$ significance level 0.1 
Table 7: Estimation results of the Quantile Regression for the total model (M5) to identify impact of the relation between Social Sciences and Sciences

Endogenous Variable: Efficiency

\begin{tabular}{|c|c|c|}
\hline Variable & $\begin{array}{c}\text { 25\%-Quantile } \\
\text { Coefficient (t-value) }\end{array}$ & $\begin{array}{c}\text { 75\%-Quantile } \\
\text { Coefficient (t-value) }\end{array}$ \\
\hline Fraction of SSCI publications & $0.8223(3.36)^{* * *}$ & $0.5050(2.03)^{* *}$ \\
\hline Fraction of SSCI graduates & $-0.5419(2.17)^{* *}$ & $-0.2567(1.23)$ \\
\hline Grants & $-3.3600(1.65)$ & $-3.8900(2.21)^{* *}$ \\
\hline Students & $9.38(1.47)$ & $9.7700(1.62)$ \\
\hline Medicine & $0.1969(2.28)^{* *}$ & $0.0652(1.01)$ \\
\hline Age & $0.2190(0.01)$ & $-0.0002(0.94)$ \\
\hline $\operatorname{Age}^{\wedge} 2$ & $0.0436(0.47)$ & $0.0917(1.17)$ \\
\hline Inhabitants & $0.0410(0.19)$ & $-0.0685(0.64)$ \\
\hline West & $0.2346(2.50)^{* *}$ & $0.2369(3.11)^{* * *}$ \\
\hline $\mathrm{H}$ & $0.0350(0.12)$ & $-0.2906(1.15)$ \\
\hline No of universities & $-0.1404(0.88)$ & $-0.0733(0.53)$ \\
\hline Constant & $0.4761(1.27)$ & $0.9388(3.00)^{* * *}$ \\
\hline Pseudo R-squared & 0.4370 & 0.4077 \\
\hline
\end{tabular}

The coefficients for students, grants, age ${ }^{\wedge} 2$ and inhabitants are multiplied by 100,000 .

***significance level $0.01 ; * *$ significance level $0.05 ; *$ significance level 0.1 